
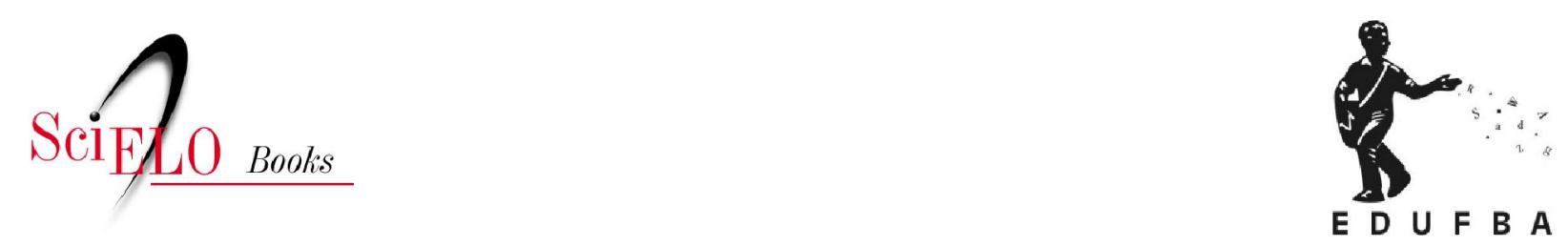

\title{
Comunicación gubernamental y condiciones del diálogo público
}

\author{
Corina Echavarría \\ Cecília Bruscoli
}

\section{SciELO Books / SciELO Livros / SciELO Libros}

ECHAVARRÍA, C., and BRUSCOLI, C. Comunicación gubernamental y condiciones del diálogo público. In: PINHO, J.A.G., ed. Artefatos digitais para mobilização da sociedade civil: perspectivas para avanço da democracia [online]. Salvador: EDUFBA, 2016, pp. 37-72. ISBN: 978-85-232-1877-5. https://doi.org/10.7476/9788523218775.0004.

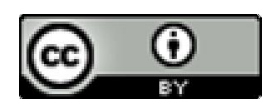

All the contents of this work, except where otherwise noted, is licensed under a Creative Commons Attribution $\underline{4.0 \text { International license. }}$

Todo o conteúdo deste trabalho, exceto quando houver ressalva, é publicado sob a licença Creative Commons Atribição 4.0.

Todo el contenido de esta obra, excepto donde se indique lo contrario, está bajo licencia de la licencia Creative Commons Reconocimento 4.0. 


\section{COMUNICACIÓN GUBERNAMENTAL Y CONDICIONES DEL DIÁLOGO PÚBLICO'}

CORINA ECHAVARRÍA, CECÍLIA BRUSCOLI

\section{INTRODUCCIÓN}

El estudio de la comunicación política es una tarea relativamente dificultosa por dos razones principales, porque en principio es todavía un concepto en disputa y porque los límites entre una rama y otra dentro del espacio de la comunicación política son difusos. (Cf. ARANCIBIA CARRIZO, 2000) Tanto que es posible distinguir diversos 'territorios de la comunicación' que se definen a partir de parámetros tanto geográficos (nacional, provincial, local, regional) como sectoriales (administración pública, sindicatos, etc). Dentro de este campo de conocimiento, particularmente, el territorio de la 'comunicación gubernamental' - local - ha constituido el foco de la atención de nuestro equipo de investigación durante los últimos años, con el objetivo de analizar las oportunidades y restricciones que experimentan los diver-

I Trabajo presentado en el XI Congreso Nacional y IV Congreso Internacional sobre Democracia, organizado por la Facultad de Ciencia Política y Relaciones Internacionales de la Universidad Nacional de Rosario (2014). Agradecemos los comentarios de los organizadores y participantes del Simposio: Impactos y desafíos de la democracia participativa. 
sos actores involucrados (gobernantes, medios y ciudadanos) a partir de factores estructurales, así como, consecuentemente, contextuales y de organización. ${ }^{2}$

Particularmente, considerando que en los procesos de ampliación o profundización democrática que apelan a la "proximidad" como condición de posibilidad de la transformación - ampliamente abordados tanto desde la ciencia política como desde la administración pública- se observa una falta de atención a la comunicación del "sector público" y sus contribuciones a la ampliación del espacio público. Las premisas que sustentan dichas propuestas, tanto teóricas como de gestión, se centran particularmente en lo que refiere a la relación gobernantegobernado. Esto es, la publicación de información gubernamental es considerada una condición necesaria de la minimización de las asimetrías de información existentes en las deliberaciones públicas que orientan la acción del Estado y, consecuentemente, una condición de posibilidad de la participación informada de los ciudadanos y ciudadanas en los procesos de toma de decisiones democráticos, de construcción de la ciudad. (Cf ANNUNZIATA, 2011; CANEL; SANDERS, 2007; DEMERS; LAVIGNE, 1998, 2007; WOLTON, 1995)

Los abordajes vinculados a la comunicación gubernamental fluctúan, entonces, en un arco de intereses entre la persuasión y el derecho a la información, entre los más destacados. Adquiriendo mayor preeminencia en la última década los debates en torno de este último, particularmente, en lo que se refiere al "acceso a la información pú-

2 Destacamos en el contexto de estos debates los trabajos realizados o en proceso de los miembros de este equipo: "Poder comunicativo y presupuesto público: materialización de las experiencias de participación ciudadana en las definiciones presupuestarias de los municipios cordobeses" , subsidiado por GRF - MinCyT Córdoba, directora: C. Echavarría, co-director: A. Buffa (2006-2007); “Democracia Deliberativa en Córdoba: análisis de los alcances y limitaciones de algunas experiencias participativas, contribuciones para su factibilidad", subsidiado por GRF - MinCyT Córdoba, directora: P. Cáceres, co-directora: C. Echavarría (2009-2011); "Pretensiones democráticas de la comunicación gubernamental: estudio de los mensajes del departamento ejecutivo de la ciudad de Córdoba (2012-2013)”, subsidiado por SeCyT-UNC, directora: C. Echavarría. 
blica"3 y la "transparencia" (en función del derecho a la propiedad y la previsibilidad de la toma de decisiones de los actores económicos), considerados una condición necesaria de la comunicación. (RIORDA, 2006) Así, la problematización de la comunicación gubernamental como sinónimo de información pública ha estado vinculada, en los procesos de Reforma del Estado, a los desarrollos referidos a la accountability horizontal - circulación de información dentro del sistema político para el control entre poderes - y vertical - oportunidades para el control ciudadano-, a la preocupación con la eficacia en el cumplimento de las funciones y tareas del gobierno (gobierno electrónico) y a la promoción de la democratización de la gestión pública (construcción de consensos, legitimación de la acción pública). Y, más recientemente, al ejercicio de los derechos ciudadanos, cuando Sobreira, Borges y Jambeiro (2007, p. 104) afirman:

[...] o não acesso a informação, o acesso reduzido ou o acesso a informações não confiáveis impede e/ou dificulta o exercício da cidadania. Diante deste fato, o acesso a informação, por tanto, se coloca como um direito de valor similar aos demais direitos do cidadão, como saúde, educação ou moradia.

Además, en trabajos anteriores advertíamos que

la discusión sobre el acceso a la información pública es más antigua que su re-edición 'transparente' y se vincula a las tensiones experimentadas por las organizaciones políticas modernas referidas a la 'publicidad' de sus formas de actuación e intervención, de los modos en que construyen la voluntad que guía la acción pública. El eje histórico de estos debates y conflictos ha estado asociado a la tensión público/secreto, esto es, a la difícil relación entre Estado y la información [...]. (BUFFA; ECHAVARRÍA, 2010, p. 101)

3 Se hace necesario distinguir el 'derecho a la información', de la garantía de 'acceso a la información pública’. Esto es, en el primer caso, la posibilidad y capacidad de los ciudadanos de buscar, recibir y difundir cualquier tipo de información, por cualquier medio existente, en un contexto de ejercicio de sus derechos garantizado por el Estado; a la que se suma, en el segundo caso, la posibilidad y protección del derecho de los ciudadanos de conocer la información generada, recibida y/o conservada por las instituciones estatales. 
La publicidad y la comunicación gubernamental como ideal normativo, representan una exigencia de visibilidad, cognoscibilidad y accesibilidad de las acciones gubernamentales y de sus criterios de adecuación a la opinión colectiva, para ser sometidos a la discusión pública formal (poder legislativo) e informal (opinión pública).

Lo anterior es de carácter fundamental para comprender la importancia de analizar las características que asume la comunicación gubernamental, más aún cuando los debates e intervenciones profesionales le adjudican una pretensión de gubermentalidad, es decir, que la práctica de comunicación de los gobiernos parte entre sus objetivos de reducir tensiones entre las demandas de los ciudadanos y las prioridades de la acción pública o gubernamental. (Cf. ELIZALDE FERNANDEZ PEDEMONTE; RIORDA, 2006)

Por todo lo dicho, en nuestro último trabajo nos propusimos analizar las características que asume la comunicación gubernamental de los departamentos ejecutivos municipales, particularmente, considerando la información y enunciados formales de autoridad (discursos, comunicados/conferencias, fundamentos de políticas y proyectos de ordenanza) publicadas en los portales los gobiernos.

Tomamos como referencia para esta empresa el modelo deliberativo de democracia que destaca la necesidad del debate, problematización y participación de los ciudadanos en la toma de decisiones, como condición de legitimidad de las acciones del Estado. Desde esta perspectiva, entonces, adquiere centralidad la participación en la construcción pública de los problemas de gobierno de los potencialmente afectados por las decisiones; así como también, la información pública, el hecho de que todos puedan hablar y la inteligibilidad de los mensajes y/o argumentos que en dichos espacios se esgrimen son condición de posibilidad de la participación. (Cf. GASTIL, 2008)

Con este enfoque deliberativo, más allá de establecer un horizonte normativo, buscamos analizar las condiciones de factibilidad para la universalización del acceso y la participación en el debate de cuestiones de interés y relevancia pública (esferas públicas reales y virtuales), en tanto garantía de la movilización e interacción de los ciudadanos en 
el decir y hacer social. (NOBRE, 2011) Considerando que, las exigencias de la comunicación pública llevada a la esfera de lo gubernamental son considerables, tanto para los políticos como para los empleados públicos. Es en este punto donde se concentran los desarrollos de este trabajo.

En tal sentido, consideramos que la comunicación gubernamental describe "rutinas" (Cf. RIORDA, 2008), a partir de las prácticas que -de modo cotidiano y no necesariamente sistematizado- dan cuenta del estilo de comunicación del gobierno y configuran un modo de entenderlo y/o de significar sus acciones ante la sociedad. Dentro del abanico de prácticas de comunicación, para analizar las formas en que se construyen los nuevos espacios participativos, en el marco de la administración municipal, pusimos nuestra atención en las páginas web de los gobiernos municipales, tomando nota de que el alcance y el volumen de la comunicación digital aumentan constantemente, si bien los estudios de la última década sostienen que los ciudadanos argentinos se informan sobre política principalmente a través de los medios de comunicación tradicionales.

Tabla 1 - ¿Cómo se informa sobre política?

\begin{tabular}{|lllllll|}
\hline & 1996 & 2000 & 2002 & 2008 & 2009 & 2010 \\
Con la familia & $29 \%$ & $30 \%$ & $43 \%$ & $46 \%$ & $44 \%$ & $53 \%$ \\
Los amigos & $18 \%$ & $20 \%$ & $28 \%$ & $32 \%$ & $35 \%$ & $42 \%$ \\
Mis compañeros de trabajo & $10 \%$ & $9 \%$ & $12 \%$ & $18 \%$ & $18 \%$ & $19 \%$ \\
Por la radio & $3 \%$ & $5 \%$ & $6 \%$ & $8 \%$ & $8 \%$ & $7 \%$ \\
Por los diarios & $56 \%$ & $51 \%$ & $59 \%$ & $60 \%$ & $60 \%$ & $66 \%$ \\
Por la televisión & $53 \%$ & $47 \%$ & $46 \%$ & $47 \%$ & $51 \%$ & $56 \%$ \\
Por Internet & $77 \%$ & $76 \%$ & $85 \%$ & $85 \%$ & $91 \%$ & $86 \%$ \\
Otros & - & - & - & $19 \%$ & $20 \%$ & $29 \%$ \\
Ninguno & $2 \%$ & $1 \%$ & $1 \%$ & $1 \%$ & $1 \%$ & $1 \%$ \\
No sabe/No responde & $3 \%$ & $7 \%$ & $1 \%$ & $2 \%$ & $4 \%$ & $2 \%$ \\
(N) & $1 \%$ & - & - & - & - & - \\
\hline
\end{tabular}

Nota: Elaborado en base a la última serie disponible de LATINOBARÓMETRO, para Argentina en la pregunta ¿cómo se informa sobre política? 
Lo dicho hasta el momento nos conduce a explorar, en primer lugar, las características que asumen las relaciones entre la comunicación gubernamental y el soporte de la comunicación digital: Internet. Para lo cual se abren distintos caminos posibles en lo que a calidad se refiere, nosotros en este trabajo nos remitiremos a los atributos del diseño y contenidos de las interfaces, considerando que son estas las que modelan la interacción y condicionan las posibilidades del ciudadano de acceso a la información y, consecuentemente, de participar de manera efectiva en la definición de los fines de la intervención estatal y su monitoreo.

\section{INTERNET, COMUNICACIÓN Y GOBIERNO}

El gobierno ha usado la tecnología de la computación desde que existe; sin embargo, con el boom que produjo internet a finales de los ' 90 se abrieron otras posibilidades de uso, en especial todo lo que concierne a la posibilidad de ofrecer servicios a los ciudadanos, apoyados en su carácter multimedia (incluye texto, imagen, audio y material audiovisual). Si se compara su evolución respecto a la de los medios tradicionales, la diferencia es abismal: para llegar a los 50 millones de usuarios, el teléfono tardó 74 años, la radio 38, las computadoras 16, la televisión 13 y el acceso a internet tan solo 4 años. (VEGA, 2009 Esto también lo podemos ver en la evolución que ha tenido Internet como fuente de información sobre política en los últimos años. (Cf. LATINOBARÓMETRO)

Es en este contexto, que la literatura destaca la importancia de las páginas web dedicadas a los espacios de participación, en la medida en que “[...] permita[n] (de forma sencilla, dinámica y atractiva) explicar el funcionamiento [...] a toda la población, informar de la Convocatoria a las Asambleas, realizar propuestas online, y permitir el seguimiento en la ejecución de las propuestas finalmente priorizadas." (FRANCÉS GARCÍA; CARRILLO CANO, 2008, p. 73) Esto es, informar sobre las características del espacio participativo, mantener actualizada la agenda de su funcionamiento, habilitar el uso de la voz en los procesos decisorios y facilitar el monitoreo ciudadano del proceso y de la ejecución de las decisiones allí tomadas. 
La publicidad y la comunicación gubernamental son tensionadas, entonces, en términos de 'accesibilidad', considerando que "when websites, web technologies, or web tools are badly designed, they can create barriers that exclude people from using the Web"4 $\mathrm{y}$, consecuentemente, de la información necesaria para la toma de decisiones. Esto es, mientras más y mejor información tenga una persona sobre un hecho o asunto (acceso a la información no se refiere solamente a "cantidad" sino - y sustancialmente - a "calidad": veraz, certera, actualizada y pertinente), son mayores sus posibilidades de actuar para conseguir los resultados que desea obtener, en nuestro caso, para participar.

\section{REPENSANDO LA ACCESIBILIDAD}

La accesibilidad es definida como "[...] la posibilidad de que un sitio o servicio web pueda ser visitado y utilizado de manera satisfactoria por el mayor número posible de personas, independientemente de las limitaciones personales que tengan o aquellas limitaciones que sean derivadas de su entorno". (INTECO, 2008, p. 5) En tal sentido, la discusión sobre accesibilidad en el contexto de los espacios destinados a la participación ciudadana busca poner el acento en la factibilidad del acceso universal que supone la web, esto es, relevar las condiciones contingentes en las que dicho principio se desarrolla. Tales como que el público al que se dirige la información referida a espacios participativos es heterogéneo, se compone de ciudadanos y ciudadanas cuyas competencias comunicativas y de manejo del medio para interactuar con diseños complejos varían considerablemente. Otra diferencia radica en que, a pesar de la proliferación tecnológica, no todos los sectores sociales cuentan con acceso a internet, por lo que muchas personas acceden desde lugares públicos tales como los denominados cyber. Además de reconocer que para el 'usuario' web, que posee las competencias y capacidades necesarias, resulta más agradable y hasta un incentivo navegar por un sitio en el que no tiene que 'investigar' dónde

4 Como afirma el World Wide Web Consortium, una organización internacional que desarrolla estándares abiertos para la programación web, procurando asegurar el crecimiento de la web. Ver: World Wide Web Consortium. 
se encuentra la información, sino que puede acceder a ella de manera rápida y efectiva, disminuyendo los costos de la participación al menos en términos de tiempo.

En términos generales los principios del diseño accesible refieren a: la igualdad de uso, la flexibilidad respecto de las preferencias y habilidades individuales respecto de mecanismos y ritmos de interacción, el carácter simple e intuitivo, la facilidad tanto para el aprendizaje en el uso de la interfaz como para la percepción de la información a través de la misma (comprensible), la tolerancia a los errores de los usuarios, el escaso esfuerzo físico requerido para el uso y las dimensiones apropiadas en tamaños y espacios. ${ }^{5}$ En función del presente trabajo, nos enfocamos en cuatro de estos principios que consideramos son de utilidad al momento de realizar el análisis de páginas web destinadas a procesos participativos:

- El carácter simple e intuitivo del diseño (amigable): este debe ser fácil de entender independientemente de la experiencia, los conocimientos, las habilidades o el nivel de concentración del usuario.

- La facilidad para la percepción de la información (comprensible): el diseño debe ser capaz de intercambiar información con el usuario, independientemente de sus condiciones ambientales/ contextuales o sus capacidades sensoriales.

- Escaso esfuerzo físico: el diseño debe poder ser usado eficazmente y con el mínimo esfuerzo posible (por ejemplo, evitando las acciones repetitivas).

- Dimensiones apropiadas: los tamaños y espacios deben ser apropiados para su manipulación y uso por parte del usuario, independientemente de su tamaño, posición, y movilidad.

Con base en estas pautas, hemos construido tres dimensiones de análisis, a saber: identificación, usabilidad y contenido.

5 El Instituto Nacional de Tecnologías de la Comunicación (Inteco) de España, ha trabajado -desde su centro de referencia en accesibilidad y estándares web- en la elaboración de guías prácticas de comprobación de accesibilidad”, los parámetros utilizados en este trabajo parten de los propuestos en la guía denominada "Introducción a la accesibilidad web”. (INTECO, 2008) 
La identificación hace referencia a la posibilidad de reconocimiento del sitio web y de los servicios que ofrece por parte del usuario. Sus indicadores son:

- características de la dirección del sitio web (URL) y de sus páginas internas;

- la existencia de logotipos y eslogans;

- la presencia de datos de contacto e información acerca de la repartición a cargo del la implementación del proceso;

- la explicitación de objetivos de la página interna y su correlación con los servicios que ofrece;

- fuentes y fechas de los contenidos.

Cabe estacar que los expertos en User Experience (UX) diferencian entre el diseño 'accesible' y 'usable'. Mientras las accesibilidad, para estos especialistas, refiere a la posibilidad de que la información pueda ser visualizada desde cualquier dispositivo (o en una gran mayoría de ellos), la usabilidad refiere a la simplicidad, rapidez y posibilidad de acceder a la información, sin obstáculos ni ayuda de terceros, incluso en situaciones de alguna imposibilidad física por parte del usuario, aproximándose a las discusiones sobre accesibilidad tal y como las hemos presentado más arriba. ${ }^{6}$ Siempre considerando que un diseño no es usable en sí mismo en función de sus usuarios potenciales y contextos especiales de uso (en nuestro caso: vecinos de la ciudad que participan, pero también aquellos que no participan, de los espacios existentes para la toma colectiva de decisiones). En este sentido, entonces, observamos las páginas web municipales distinguiendo la navegabilidad y el diseño.

6 Cabe destacar que la Convención de los Derechos Humanos para personas con discapacidades (realizada en diciembre 2006) establece el acceso a la información como un Derecho Humano Básico, igualado a otros como vivienda, educación, salud. Entonces, en la literatura, cuando se habla de accesibilidad web se habla de diseños que permitan la navegación para todo tipo de usuarios, incluyendo a aquellos que no tienen discapacidades pero presentan otro tipo de dificultades como la edad, escasos recursos tecnológicos, ambientes poco propicios y poco conocimiento sobre el uso de tecnologías. (Cf. W3 $\mathrm{C}, 2015$ ) 
La navegabilidad nos refiere a todos los aspectos que ayudan al usuario a navegar por el sitio, es decir, a la estructura de navegación. Los indicadores que hemos tomado para esto son:

- formas de acceder a la información;

- longitud de la página;

- características y estado de los enlaces;

- elementos que orientan al usuario (breadcrums, enlaces para regresar);

- compatibilidad del sitio con diferentes navegadores;

- software necesario para visualizar correctamente la información;

- posibilidad de imprimir;

- recursos de búsqueda;

- secciones de ayuda.

- Mientras que el ‘diseño’ nos remite a las cuestiones estéticas de la interfaz, donde adquieren relevancia:

- uso de colores;

- espacios (separación en párrafos y/o unidades de sentido);

- tipografías;

- 'limpieza'.

Finalmente, el contenido, nos pone en contacto con la información propiamente dicha publicada en los sitios web. En tal sentido, los indicadores que construimos derivan de las características usualmente asociadas a la información pública, tales como veracidad, oportunidad, inteligibilidad y/o sencillez.7 Así como también específicamente para los casos considerados:

- disponibilidad de información básica sobre el proceso participativo (qué es, cómo funciona, quiénes pueden participar, cuáles son los objetivos);

- publicación de sus cronogramas;

7 Cf. BUFFA; ECHAVARRÍA, 2011 
- existencia de espacios de intercambio de opiniones entre el Estado y los ciudadanos (foros y correo electrónico);

- instrumentos de transparencia (proyectos votados; cantidad de asistentes; avances de ejecución de proyectos que permitan el monitoreo ciudadano);

- lenguaje y redacción (amigable, cercano, formas de nombrar a los actores involucrados).

\section{LOS CASOS CONSIDERADOS}

Desde el retorno a la democracia en 1983, el principio representativo que sustenta nuestra democracia ha sido constantemente tensionado. En especial luego de la crisis de 2001 que obligó a repensar las formas de ejercicio del poder que se manejaban hasta entonces, los gobiernos locales necesitaron desarrollar acciones en orden a dar respuesta urgente en sus contextos particulares a las desigualdades económico-sociales que enfrentaba el país, pero también para recuperar legitimidad social de las formas de acción privilegiadas.

Se puso en agenda, entonces, la revisión de los fundamentos de legitimidad que sustentan la intervención del Estado en sus distintos niveles, para que el sistema político administrativo pudiera acceder a la habilitación de las voces con poder para incidir en la formulación de políticas. (Cf. ECHAVARRÍA, 2011a) En este contexto y a simple vista, las ciudades argentinas parecían atravesar un proceso de profundización de la democracia y de promoción de la ciudadanía activa. Discursos y tecnologías, desarrollos institucionales promovidos en los niveles nacional y trasnacional, confluyeron estratégicamente en el espacio local, donde fueron adoptados y después socializados en comprensiones domésticas. Particularmente en lo que respecta al conjunto de lineamientos que orientan la discusión y definición del Presupuesto Participativo, como institución para la gestión participativa de los recursos públicos, cuya implementación se multiplica en este nuevo siglo a lo largo del país. Los diversos análisis atribuyen su difusión a la necesidad de legitimación referida, apelando al potencial de la proximidad y de redistribución del "dispositivo" de gestión. 
El caso del PP de Porto Alegre sirvió como referencia para su implementación en distintas ciudades argentinas en lo que, parafraseando a Dagnino, podríamos denominar una "confluencia perversa" 8 con las experiencias de microplanificación estratégica características de la década de los '90. De hecho, son estas microplanificaciones las que se reconocen en las distintas ciudades como antecedentes del PP en términos de prácticas de gestión participativa.

Los casos de Presupuesto Participativo que, desde entonces, más difusión han obtenido en Argentina son los implementados en las ciudades de Morón, Rosario y Córdoba. El Municipio de Morón está ubicado en el centro del Área Metropolitana de la provincia de Buenos Aires, al oeste de la Ciudad Autónoma de Buenos Aires, tiene una población de 321.109 habitantes (Censo Nacional 2010) y es gobernado una fuerza política de centro izquierda de origen vecinalista Nuevo Morón (Nuevo Encuentro a nivel nacional) que accede a fines de la década del noventa a través del triunfo de la Alianza. La ciudad de Rosario está ubicada en la zona sur de la provincia de Santa Fé, tiene una población de 1.193.605 habitantes (Censo Nacional 2010) y se encuentra gobernada por Frente Progresista Cívico y Social (liderado por el Partido Socialista) desde la década de noventa. La ciudad de Córdoba es la ciudad capital de la provincia de Córdoba, en el centro geográfico de la Argentina y en términos poblacionales es el segundo centro urbano del país (1.330.023 habitantes, según el Censo Nacional 2010); desde finales de la década de noventa ha sido gobernada alternativamente por diversas fuerzas políticas (Unión por Córdoba, Frente Cívico y Social y Unión Cívica Radical). En tal sentido, estos casos dan cuenta de lo que afirmáramos en otros trabajos, la implementación de PP en Argentina no ha estado asociada a una fuerza política en particular.

\footnotetext{
8 Dagnino (2006) utiliza este término para referirse a la confluencia entre el proyecto neo-liberal y su correspondiente configuración del Estado y los proyectos participativos de la profundización de la democracia que se difunden en Latinoamérica. Dicha confluencia sería perversa ya que los sentidos de la participación ciudadana y del proyecto neo-liberal son diferentes y hasta opuestos.
} 
Cuadro 1 - Ciudades, partidos y "pasadores"

\begin{tabular}{|l|l|l|l|l|}
\hline CIUDAD & INSTITUCIÓN & AÑO & $\begin{array}{l}\text { ACTORES } \\
\text { VINCULADOS A LA } \\
\text { IMPLEMENTACIÓN }\end{array}$ & $\begin{array}{l}\text { PARTIDO EN } \\
\text { EL GOBIERNO }\end{array}$ \\
\hline $\begin{array}{l}\text { Rosario } \\
\text { (pcia de Sta. Fe) }\end{array}$ & $\begin{array}{l}\text { Presupuesto } \\
\text { Participativo }\end{array}$ & 2002 & $\begin{array}{l}\text { Universidad } \\
\text { Nacional de Rosario }\end{array}$ & $\begin{array}{l}\text { Frente } \\
\text { Progresista } \\
\text { Cívico y Social } \\
\text { (socialismo) }\end{array}$ \\
\hline $\begin{array}{l}\text { Morón } \\
\text { (pcia de Bs. Aires) }\end{array}$ & $\begin{array}{l}\text { Presupuesto } \\
\text { Participativo }\end{array}$ & 2006 & $\begin{array}{l}\text { NUEVO } \\
\text { ENCUENTRO } \\
\text { (d. 1999 Martín } \\
\text { Sabatella) }\end{array}$ \\
\hline $\begin{array}{l}\text { Córdoba } \\
\text { (pcia de Córdoba) }\end{array}$ & $\begin{array}{l}\text { Presupuesto } \\
\text { Participativo }\end{array}$ & $\begin{array}{l}2008 \\
2005\end{array}$ & $\begin{array}{l}\text { Área Prácticas } \\
\text { Participativas de } \\
\text { Gestión Asociada / } \\
\text { FLACSO }\end{array}$ & $\begin{array}{l}\text { Frente Cívico y } \\
\text { Social }\end{array}$ \\
\hline
\end{tabular}

Fuente: adaptado de ECHAVARRÍA, 2011b.

Tabla 2 - Presupuestos Municipales

\begin{tabular}{l|l|l|l}
\hline CIUDAD & $\begin{array}{l}\text { PRESUPUESTO } \\
\text { TOTAL (2012) }\end{array}$ & PP & \% PP/Pres T \\
\hline Morón & 617.490 .000 & $3.615 .264 *$ & 0,59 \\
\hline Rosario & 2.900 .371 .301 & $42.000 .000 * * *$ & 1,45 \\
\hline Córdoba & 3.215 .018 .809 & $40.154 .079 * * *$ & 1,24 \\
\hline
\end{tabular}

Fuente: adaptado de Buffa-Echavarría, 2012. *monto variable decidido por el Poder Ejecutivo. $* *$ montos derivados de porcentuales definidos por ordenanza municipal.

En el caso de los dos primeros, tenidos como exitosos, su suceso se asocia sobre todo en los flujos crecientes de participación que experimentaron en los primeros años de implementación, a diferencia de la ciudad de Córdoba (Córdoba) que no ha tenido la misma penetración en la sociedad a pesar o quizás por las diversas tentativas de implementación que se sucedieron desde 2001. (Cf. ECHAVARRÍA; ROMANUTTI, 2014)

Rosario fue la primera ciudad en implementar PP (2002), 9 en un contexto en el que se habían ensayado otras alternativas posibles de ca-

9 En el Concejo Deliberante de la ciudad de Rosario se registran diversos proyectos de PP anteriores a su implementación definitiva: 2000 del bloque Unidad de la Izquierda y la Resistencia 
rácter gerencial, donde la participación se concretaba esporádicamente y a través de distintos niveles de reconocimiento y de decisión: actores "relevantes" en la construcción de la ciudad (planificación estratégica de ciudad en los años 1996 y 2002); los vecinos para integrar diagnósticos en los barrios y Distritos (micro-planificación participativa a escala barrial y jornadas participativas de Distrito, de carácter consultivo en 1989 y 2001). Si bien no es posible identificar una única razón que explique la decisión gobierno de optar por el PP, Ford (2007) advierte que su puesta en marcha se dio en el marco de una concepción gradualista y consultiva propia del denominado "modelo catalán" ${ }^{\circ \circ}$ de la participación: “[...] siempre se habló del ciudadano al estilo del que hablan los documentos técnicos de la descentralización en la línea de los catalanes [en los que] la participación se ve como el sucedáneo legitimado frente a la pura eficiencia técnica". (FORD, 2007, p. 55)

En Córdoba, el antecedente inmediato del PP es también la micro-planificación estratégica, que se implementó durante de la década de '9o en algunos barrios de la ciudad, al mismo tiempo que la ciudad era pensada para el mediano y largo plazo en lo que se conoció como Plan Estratégico para la Ciudad de Córdoba (PEC). A pesar de diversos intentos de implementación que se registran pos crisis del 2001, será recién en 2004, cuando una experiencia participativa en el gobierno municipal reciba el nombre de PP, para ser reconocido normativamente en 2008 en estrecho vínculo con otra institución incorporada a la estructura municipal: las juntas de participación vecinal.

En el caso de Morón, la implementación del PP tiene lugar a partir de 2006 , con un diseño apoyado en el de Rosario. En un municipio que era considerado como "la capital de la corrupción", la institución se presenta como respuesta a las demandas por de transparencia.

(UNIR) y vuelto a presentar por el PPS (Partido del Progreso Social) en el mismo año; 2001, el Frente Grande, convocó a una Audiencia Pública no vinculante para discutir el presupuesto municipal 2001, en la que el PP se menciona de manera reiterada. (Cf. FORD, 2007)

10 Tanto la experiencia de Rosario como la de Córdoba reconocen claramente la impronta del modelo de planificación que se desarrolló en Barcelona en ocasión de los preparativos de la ciudad para sediar los juegos olímpicos a inicios de la década del noventa, que incluida la identificación/diferenciación de diferentes niveles de planificación - micro, meso y macro. 
En el siguiente cuadro identificamos los momentos de la participación que describe el proceso del PP en los tres casos considerados en este trabajo.

\author{
Cuadro 2 - El proceso participativo en las experiencias argentinas de \\ Presupuesto Participativo
}

\begin{tabular}{|c|c|c|}
\hline ROSARIO (2002) & CÓRDOBA (2004) & MORÓN (2006) \\
\hline Asambleas Barriales & $\begin{array}{l}\text { Cabildos/Asambleas a } \\
\text { escala barrial o zonal }\end{array}$ & $\begin{array}{l}\text { Reuniones barriales o } \\
\text { Asambleas por zonas }\end{array}$ \\
\hline \multicolumn{3}{|c|}{$\begin{array}{l}\text { Asamblea en la que con la participación de los vecinos de la zona de referencia se } \\
\text { identifican ideas, propuestas y/o problemas (diagnóstico de la situación barrial, en el caso } \\
\text { de Córdoba en el período } 2004-2011 \text { esto también incluía una "priorización de problemas") } \\
\text { y se eligen representantes vecinales para participar de la elaboración de proyectos referidos } \\
\text { a los resultados de la misma. }\end{array}$} \\
\hline $\begin{array}{l}\text { Consejos Participativos } \\
\text { de Distrito, redactan los } \\
\text { proyectos y envío a las } \\
\text { distintas secretarias para su } \\
\text { evaluación }\end{array}$ & $\begin{array}{l}\text { Talleres de presupuesto } \\
\text { participativo (x zona } \\
\text { barrial se redactan los } \\
\text { proyectos asociados a los } \\
\text { problemas identificados) }\end{array}$ & $\begin{array}{l}\text { Consejos Vecinales: elabora } \\
\text { un informe territorial, } \\
\text { que luego será analizado } \\
\text { por las distintas áreas del } \\
\text { gobierno }\end{array}$ \\
\hline \multicolumn{3}{|c|}{$\begin{array}{l}\text { En los tres casos los técnicos municipales participan de las reuniones junto a los vecinos, } \\
\text { se prevé alguna forma de información y/o capacitación para los representantes vecinales }\end{array}$} \\
\hline Estudios de factibilidad & & $\begin{array}{l}\text { Las áreas temáticas } \\
\text { del gobierno, que han } \\
\text { recibido los informes de } \\
\text { cada territorio, elaboran } \\
\text { proyectos }\end{array}$ \\
\hline $\begin{array}{l}\text { Reuniones de las áreas de } \\
\text { gobierno con los CPD para } \\
\text { informar estas evaluaciones, } \\
\text { como así también buscar } \\
\text { alternativas a los que tienen } \\
\text { factibilidad negativa }\end{array}$ & & $\begin{array}{l}\text { Ronda de consultas: los } \\
\text { funcionarios presentan los } \\
\text { pre-proyectos a los vecinos } \\
\text { para discutir alternativas a } \\
\text { lo planificado }\end{array}$ \\
\hline $\begin{array}{l}\text { Confección de lista de } \\
\text { proyectos a votar en la } \\
\text { Segunda Ronda y difusión }\end{array}$ & & $\begin{array}{l}\text { Las áreas del gobierno } \\
\text { finalizan la elaboración de } \\
\text { proyectos }\end{array}$ \\
\hline $\begin{array}{l}2^{\circ} \text { Ronda de Elección de } \\
\text { Proyectos }\end{array}$ & $\begin{array}{l}\text { Votación de proyectos } \\
\text { (desde 2013) }\end{array}$ & Ferias de Proyectos \\
\hline $\begin{array}{l}\text { Jornada de cierre - } \\
\text { Evaluación del Proceso } \\
\text { de PP del año en curso / } \\
\text { Encuentros Interdistritales }\end{array}$ & & $\begin{array}{l}\text { Comisión de Seguimiento } \\
\text { (personas designadas por } \\
\text { cada Consejo Vecinal) }\end{array}$ \\
\hline
\end{tabular}

Fonte: Adaptado de Echavarría (2013). 
A continuación presentamos el análisis de los sitios web de los tres municipios considerados, teniendo en cuenta dos unidades de observación: el home o página de inicio de cada uno de los gobiernos municipales, y las respectivas páginas internas referidas al PP. Para este trabajo se realizó un seguimiento a intervalos regulares durante el período 2012-2013.

\section{Identificación}

Las URL de las 3 páginas web de los municipios son sencillas y fáciles de recordar. Se construyen con el nombre del mismo (Rosario, Moron y Córdoba) y la extensión .gov o .gob. Mientras que en lo que respecta a las páginas internas destinadas a los espacios de participación, solamente en el caso de Morón la URL comparte esas características, dado que suma a la dirección principal las palabras "presupuesto participativo" (indicando la separación de los términos por la barra oblicua que se utiliza para construir URLS). Mientras que en el caso de Rosario ya presenta cierto grado de dificultad al incorporar dos tramos intermedios (sitio, información-municipal) antes de 'pp' y la página interna de Córdoba resulta inaccesible para recordar de memoria, ya que demanda reproducir la secuencia del organigrama municipal hasta llegar a la dependencia responsable del proceso participativo:

- http://www.moron.gov.ar/presupuestoparticipativo

- http://www.rosario.gov.ar/sitio/informacion_municipal/pp.jsp

- http://www2.cordoba.gov.ar/portal/index.php/secretaria-degobierno/subsec-de-participacion-ciudadana/direccion-de-presupuesto-participativo/

En lo que se respecta a los objetivos del sitio, Rosario los presenta en la sección "Bienvenida”, mientras que las páginas de Córdoba y de Morón no presentaban objetivos generales del sitio y en sus páginas internas tampoco presentan objetivos de las mismas, lo cual presupone un usuario conocedor de los contenidos que allí se ponen a disposición y de su importancia y pertinencia para el proceso participativo. 
A su vez, Rosario es el único municipio que cuenta con un logotipo (inclusive traducido a la lengua Quom) que permite identificar clara y rápidamente, más allá de los colores, el sitio gubernamental y, particularmente, la información referida al PP. Finalmente, ninguna de las tres ciudades posee un eslogan, que en la página interna refuerce los ejes que orientan la implementación del espacio participativo en el contexto de la gestión o coyunturalmente en el año de intervención.

Con respecto a los datos de contacto, todos los sitios ponen a disposición del ciudadano usuario de la web algún tipo de contacto, desde las más tradicionales, como el número de teléfono de la repartición responsable y la dirección física de la misma (Córdoba), pasando por el correo electrónico que permita un intercambio en el mismo soporte en que el vecino se aproxima o busca información (Morón y Rosario), hasta la previsión de una línea telefónica gratuita (Rosario), que busca eliminar las diferencias de recursos existentes entre los ciudadanos para la participación.

Cuadro 3 - Identificación

\begin{tabular}{|l|c|c|c|}
\hline CIUDAD & \multirow{2}{*}{ CÓRDOBA } & ROSARIO & MORÓN \\
\cline { 1 - 3 } INDICADORES & $x$ & $x$ & $x$ \\
URL HOME clara y fácil de recordar & & $x$ & $x$ \\
URL de página interna, clara y fácil de recordar & & $x$ & \\
Existencia de objetivos del sitio & & $x$ & $x$ \\
Existencia de logotipo & & $x$ & $x$ \\
Existencia de slogan & $x$ & $x$ & $x$ \\
Datos de contacto con la institución & $x$ & $x$ & \\
-Teléfono & & $x$ \\
-Dirección Postal & & $x$ \\
-Correo Electrónico & & $x$ \\
-Otros & & $x$ & \\
\hline
\end{tabular}

Fonte: Elaboración propia.

Por último, respecto a fuentes y fechas de publicación, que permiten al ciudadano usuario valorar la actualidad, pertinencia y relevancia de la información que accede en el sitio, son datos que están presentes 
en los casos de Rosario y Morón, inclusive en este último el usuario web puede ver la cantidad de veces que cada materia ha sido visitada. Mientras que en el caso del sitio cordobés solamente en algunos casos aparecen las fechas de actualización y no se citan las fuentes de las noticias incorporadas.

\section{Usabilidad}

\section{Navegabilidad}

En estrecho vínculo con la identificación de la información que el ciudadano está buscando, cuando comenzamos a analizar la navegabilidad, el denominado "posicionamiento" de los elementos es clave, ya que el recorrido que hace el usuario con la vista describe un recorrido típico: izquierda-derecha-abajo. Por ese motivo, los expertos en usabilidad recomiendan ubicar el logo (identificación) a la izquierda y arriba, para que el usuario sepa dónde está. Después del logo, la estructura de navegación, para que sepa rápidamente a dónde ir, y a continuación el contenido destacado y normal.

En el caso de Rosario, la página de inicio posee un menú vertical ubicado a la izquierda, con diferentes vínculos. Al PP se puede acceder desde "Gestión", desde "Administración Financiera" (que se encuentra dentro de "Información Municipal”), y desde un menú desplegable ubicado arriba a la derecha (que se corresponde a la opción de "navegación" descrita más arriba), donde el PP se encuentra en zer lugar entre 48 disponibles. De esta manera la información sobre el espacio de participación tiene un total de 3 accesos posibles. Si bien, en los dos primeros, se asume que el usuario sabe que el PP se relaciona a las actividades de la Gestión o a la Administración Financiera, estos “nombres" podrían asumirse como fácilmente relacionables con el PP. No obstante lo cual, sería recomendable avanzar en un estudio de percepción del usuario al respecto.

Al igual que en la anterior, en la página de Inicio de la web de Morón hay un menú vertical ubicado a la izquierda con diferentes vínculos. Al PP, en este caso, se puede acceder desde los enlaces: "Organizaciones comunitarias” y “Desarrollo Estratégico”. Además, ofrece un 
vínculo propio, destacado con una imagen gráfica en un menú vertical ubicado a la derecha. De esta manera, la página principal tiene un total de 3 accesos, además de la opción "mapa del sitio" (si bien este enlace no estaba funcionando correctamente durante el período relevado).

Finalmente, la mayor complejidad en términos de posicionamiento lo encontramos en la página de inicio del municipio de Córdoba. Como en las anteriores, en el inicio hay un menú vertical ubicado a la izquierda, que contiene diferentes links que responden a la organización funcional del municipio. De esta manera, a la información sobre PP se puede acceder desde "Secretaría de Gobierno", a través de "Subsecretaría de Participación Ciudadana y Desarrollo Social”. Este recorrido es la única posibilidad de acceso. Decimos que es la más compleja o 'difícil' para el usuario, en principio, porque asume que el usuario sabe que el PP se encuentra dentro de la Secretaría de Gobierno, instancia de la que depende la "Subsecretaría de Participación Ciudadana y Desarrollo Social” encargada de la implementación del proceso participativo. Pero además, porque en este menú, finalmente no se despliega la opción de vínculo a la información buscada, sino que procede a desplegar otro menú vertical a la derecha en cuyo interior se encuentra la opción “Dirección de Presupuesto Participativo". Es decir, que el usuario debe advertir que el camino que venía realizando cambió sin previo aviso y sin especificar hacia dónde. Además, en ese nuevo menú los nombres de los vínculos aparecen cortados, por lo tanto, es necesario posicionar el mouse sobre cada uno de los links para saber cuál es el del PP.

En las discusiones sobre navegabilidad entre los diseñadores y programadores web, el "mito de los 3 clicks" ha sido muy difundido, asumiendo que si el usuario se ve obligado a hacer más de 3 clicks para llegar a aquello que busca, termina saliendo de la página. Sin embargo, distintos estudios ${ }^{\text {II }}$ demuestran que esto no es así, ya que al usuario no le molestaría la cantidad de clicks mientras pueda llegar a eso que busca sin problemas. Como afirma el experto en UX/UI Carlos Bruscoli,

11 Ver User Interface Engineering, 1997-2015. 
Lo más importante en la web/formato digital, es que el contenido llegue correctamente a los usuarios [...]. Una práctica importante es identificar cuáles son los contenidos principales para poder darles un lugar de fácil y rápido acceso, evitando así que el usuario tenga que hacer +2 clicks para llegar al punto más importante de la aplicación/website. (C. BRUSCOLI, entrevista, 26 de marzo de 2014)

Así de acuerdo a lo expuesto anteriormente, en la página de Córdoba, para acceder al PP hay que hacer 4 clicks, y para llegar hasta la ordenanza que contiene la información básica, 6. Mientras que en la página de Rosario, con dos clicks es suficiente para acceder a la información sobre el PP y en la de Morón, por su parte, con un click es suficiente para acceder a la información sobre el PP.

La página interna del PP de Córdoba se encuentra condensada en una sola página, por lo tanto obliga a scrollear (desplazar línea a línea) para acceder a los contenidos que ella se publican. Además, dicha la página posee un header o encabezado fijo para todas las páginas internas del sitio, con las novedades de la acción de gobierno (noticias), que ocupa casi la mitad superior de la pantalla; por lo que siempre es necesario scrollear para visualizar la información a la que se intenta acceder. Con respecto al scrolling, Loranger (2014) afirma que puede ser un reemplazo elegante para la paginación, pero que “[...] it’s not the answer for most websites. Infinite scrolling is probably not for you if site visitors want to achieve goal-oriented activities, such as when they need to backtrack or find specific information quickly." Además, la autora explica que el scrolling "paraliza" al usuario ya que no tiene necesidad de hacer click para acceder a más información. También es un tipo de diseño que genera ansiedad, como un "abismo de información”, solamente jerarquizada según la última actualización.

Mientras que Rosario y Morón, por su parte, tienen la información distribuida por paginación, por lo tanto para acceder a la información hay que hacer click en los enlaces que indican las distintas secciones. De esta manera es la estructura de la navegación la que da cuenta de las jerarquías en los contenidos en la página. 
Los enlaces también son importantes en cuanto a la navegabilidad, ya que son los que nos permiten ir desde un punto de la página hacia otro, es decir, de una información hacia otra. Por lo tanto, es importante poder reconocerlos fácilmente, y además estos deben funcionar. En la página de Córdoba, algunos enlaces son difíciles de reconocer, dado que como afirmáramos anteriormente los nombres aparecen incompletos (enlaces que ocupan más de una línea) y se hace necesario posicionar el mouse sobre dichos enlaces para poder leerlos completos, también hay enlaces que no llevan a ningún sitio y otros que llevan al diseño anterior de la página, como el de Presupuesto, donde aparece el mensaje "presione el siguiente link y será re-direccionado al nuevo portal de la Municipalidad de Córdoba”. En los casos de Rosario y Morón los contenidos asociados al municipio y al PP son fácilmente reconocibles ya que el texto es de otro color. No existen enlaces "rotos", todos funcionan y es posible acceder a la información desde el año 2003, cuando se implementó por primera vez el PP en el municipio de Rosario, y desde el año 2006, cuando se implementó por primera vez el PP en el municipio de Morón (si bien este dato podría ser atribuible a otras razones que exceden al diseño como la continuidad de la fuerza política en el gobierno de la ciudad).

Los enlaces también aparecen en forma de elementos que orientan al usuario, por ejemplo aquellos que permiten volver a la página anterior. Estos son muy útiles ya que ofrecen una experiencia de uso más agradable al permitir que el usuario evite subir y bajar por toda la página o volver a hacer click en las secciones a las que quiere acceder. En este sentido, se destaca el sitio rosarino que ofrece, cuando se revisa o accede a cualquier información, en la parte superior de la página un enlace para volver al principio o atrás. Los sitios de Córdoba y de Morón no tienen estos elementos de navegación que orienten al usuario, pero todos los links de acceso permanecen fijos a la derecha, dejando visible la estructura de la misma.

En un nivel más técnico, la compatibilidad del sitio con diferentes navegadores y el software necesario para visualizar correctamente la información son aspectos fundamentales si queremos hablar de acce- 
sibilidad. Por eso, durante los diversos accesos hemos probado acceder a los sitios desde los navegadores Google Chrome, Safari, Mozilla Firefox e Internet Explorer, y en todos ellos las páginas funcionan correctamente, por lo tanto son compatibles. No obstante lo cual, independientemente del navegador, todas las páginas requieren de software adicional para visualizar correctamente la información, tales como software que permite ver imágenes en movimiento. Es en la página de Rosario, al pie, que se advierte en algunas secciones la necesidad del uso de Flash (para visualizar imágenes en movimiento) y de Adobe Reader (para leer archivos de extensión .pdf); así como también que el mismo sitio facilita su descarga en el caso de que sea necesario.

Otra recomendación al momento de realizar una página web es hacerla pensando en que pueda ser impresa, ya que hay muchos usuarios que - por distintos motivos - prefieren o necesitan imprimirla. En este caso, solamente la página de Córdoba no se puede imprimir sin problemas. En primer lugar, no hay opciones de impresión en la propia página, y cuando se marca esa opción desde el navegador que se está usando el formato de la página se "desarma" y la información no queda organizada para imprimirla correctamente. En los casos de Rosario y Morón, si bien tampoco presentan la opción de imprimir en la misma página, desde el navegador se accede y la vista previa la información aparece organizada exactamente igual que en la página web, es decir que el diseño está pensado para que sea imprimible.

Los recursos de búsqueda también son necesarios y útiles para encontrar más rápido y en forma más sencilla la información que buscamos. Las páginas de Córdoba y Rosario ofrecen navegadores en sus páginas de inicio, no así Morón. En el caso de Córdoba, no permite una búsqueda avanzada: el buscador solamente permite ingresar palabras clave, con una caja de texto es infinita. El navegador de Rosario permite la búsqueda por palabras y números de más de 3 caracteres y también permite realizar búsquedas específicas, mediante un formulario de búsqueda avanzado. En este caso, la caja de texto posee un límite de 40 caracteres. En la página de Morón, como se dijo, no hay opción de bús- 
queda excepto en algunas secciones (que no están relacionadas al PP). En dichos casos, la búsqueda es avanzada y la caja de texto es infinita.

Los resultados de las búsquedas se muestran de manera clara en todos los casos, pero solamente Rosario asiste al usuario en el caso de que la búsqueda sea infructuosa. La mencionada página arroja un enlace para realizar una "Nueva búsqueda" sin tener que volver al buscador y además ofrece ayuda sobre cómo buscar.

Por último, las secciones de "Ayuda" ofrecen al usuario respuestas a las posibles preguntas que le pueden surgir durante la navegación, como por ejemplo dónde encontrar alguna información o cómo realizar alguna acción. Ninguna de las páginas posee una sección de ayuda, excepto la de Rosario que presenta un enlace de ayuda dentro del buscador, que como decíamos explica cómo realizar una búsqueda exitosa.

Cuadro 4 - Usabilidad de sitios web municipales

\begin{tabular}{|c|c|c|c|}
\hline & CÓRDOBA & ROSARIO & MORÓN \\
\hline Cantidad de accesos a página interna & 1 & 3 & 3 \\
\hline Cantidad de clicks para acceder & 4 & 2 & 1 \\
\hline Enlaces fácilmente reconocibles & & $x$ & $x$ \\
\hline Existencia de enlaces rotos & $x$ & & \\
\hline Elementos de orientación & & $x$ & \\
\hline Control de longitud de página & & $x$ & \\
\hline $\begin{array}{l}\text { Compatibilidad del sitio con distintos } \\
\text { navegadores }\end{array}$ & $x$ & $x$ & $x$ \\
\hline $\begin{array}{l}\text { Necesidad de software adicional para la } \\
\text { correcta visualización }\end{array}$ & $x$ & $x$ & $x$ \\
\hline Posibilidad de imprimir correctamente & & $x$ & $x$ \\
\hline ¿Permite la búsqueda avanzada? & & $x$ & \\
\hline Los resultados son comprensibles & $x$ & $x$ & $x$ \\
\hline Caja de texto suficientemente ancha & $x$ & $x$ & $\mathrm{x}$ \\
\hline Asistencia al usuario & & $x$ & \\
\hline Existencia de Ayuda & & $x$ & \\
\hline
\end{tabular}

Fonte: Elaboración propia 


\section{Diseño}

Una de las características más generales en el diseño es la "limpieza" de la interfaz, es decir, la minimización de ruido visual. Revisando esta característica encontramos que, en principio, la jerarquía visual ${ }^{12}$ está bien expresada dentro de las tres páginas, las que como analizamos anteriormente utilizan menús desplegables y, en los textos, diferencian claramente los títulos de los contenidos.

El sitio de Rosario presenta una interfaz limpia. La mayor parte de la página es de color blanco, lo que permite un mayor contraste con el texto y las imágenes además de permitir descansar la vista. La de Morón, por su parte, es una interfaz que presenta algunos elementos que contribuyen al ruido visual, asociados al color rojo usado de manera dominante y a las imágenes en movimiento de la botononera del menú situado a la derecha de la página, si bien posee zonas en blanco que permiten descansar la vista. En el caso de la página web de Córdoba, al acceder a la misma en primera instancia visualizamos una ventana emergente (pop-up) que va cambiando su contenido según la agenda del gobierno. La portada, como dijimos anteriormente, se mantiene fija obligando al usuario a scrollear para acceder a la información. Con predominio del color verde, se registran zonas en blanco pero son mínimas, por lo que la vista no descansa mucho. En síntesis, las páginas de Rosario y Morón usan el color negro para el texto, el cual contrasta con sus respectivos fondos (blanco en el caso de Rosario, gris en el caso de Morón), mientras la página de Córdoba usa el color gris para el texto, el cual disminuye el contraste con el color de fondo (blanco).

Es interesante mencionar que un buen diseño debería tener en cuenta que existen personas que sufren de daltonismo o que son ciegas a percibir algunos colores, por lo tanto se recomienda usar colores como azul, blanco, negro, gris. En este sentido, el verde no es un color recomendable ya que es uno de los colores que las personas con estas dificultades visuales suelen confundir.

\footnotetext{
12 Entendiendo a "jerarquía visual" como una forma de diagramación de texto donde se entiende que cierta información está contenida dentro de otra, es decir que pertenece a una parte mayor.
} 
Finalmente, cabe destacar en este punto que, para conseguir una mejor experiencia de lectura, en especial cuando se trata de artículos largos, las recomendaciones que dan los diseñadores no se remiten solamente al color, sino que tienen que ver con el uso de tipografías con caracteres separados, que los párrafos y las líneas estén lo suficientemente separados, que los títulos y los links estén diferenciados. Además se recomienda utilizar grillas de texto con un ancho de hasta 70 caracteres por línea.

Los títulos de los textos aparecen bien diferenciados en las tres páginas, no así los enlaces (ver análisis sobre navegabilidad). Respecto a los caracteres por línea, reforzando lo anterior, el sitio de Córdoba tiene un promedio de 80; el de Morón de 63 y el de Rosario de 50. Las páginas de Rosario y Morón respetan la separación entre párrafos y términos en todos sus textos; sin embargo, en la página de Córdoba hay textos que no presentan la debida separación, como por ejemplo en la publicación de los proyectos y obras para el PP 2013: todo el contenido aparece condensado y sin espacios en blanco, por lo tanto para distinguir los bloques de información hay que observar atentamente. Así, para no confundir los datos es necesario que el ciudadano realice un esfuerzo de lectura, además, demandar la utilización otros comandos para aumentar su tamaño (zoom de pantalla), lo cual se puede hacer si el usuario cuenta con los conocimientos necesarios para llevar a cabo dicha acción.

Cuadro 5 - Diseño de los sitios web municipales

\begin{tabular}{|l|c|c|c|}
\hline & CÓRDOBA & ROSARIO & MORÓN \\
\hline Interfaz limpia & & $\mathrm{x}$ & $\mathrm{x}$ \\
Jerarquía visual bien usada & $\mathrm{x}$ & $\mathrm{x}$ & $\mathrm{x}$ \\
Uso de colores & & $\mathrm{x}$ & $\mathrm{x}$ \\
Existencia de "zonas en blanco" & $\mathrm{x}$ & $\mathrm{x}$ & $\mathrm{x}$ \\
Contraste entre texto y fondo & & $\mathrm{x}$ & $\mathrm{x}$ \\
Tamaño de texto legible & & $\mathrm{x}$ & $\mathrm{x}$ \\
Separación entre párrafos/términos & & $\mathrm{x}$ & $\mathrm{x}$ \\
Ancho de texto hasta 70 caracteres & & $\mathrm{x}$ & $\mathrm{x}$ \\
\hline
\end{tabular}

Fonte: Elaboración propia. 


\section{Contenido}

Retomando la idea central del trabajo, que afirma que la información es condición de posibilidad para la participación ciudadana, la dimensión de análisis referida al contenido es en este caso en la que podremos ver la pertinencia y adecuación de la información más allá de los diseños y los obstáculos para encontrarla. Por que como afirmábamos anteriormente, si la información está completa y bien elaborada de manera que resulte significativa para el ciudadano y responda a las búsquedas del usuario, los problemas de usabilidad pasan a un segundo plano. Es decir, de nada serviría una página que cumpla con todos los estándares web y no provea de la información necesaria.

En este sentido, al comparar las páginas web de los 3 municipios encontramos que las páginas de Rosario y Morón tienen enlaces específicos dentro del PP donde explican qué es, cómo funciona, cuáles son sus objetivos, quiénes pueden participar y cuándo. La Municipalidad de Rosario, inclusive, incluye un manual donde se explica cómo hacer un Presupuesto Participativo. Mientras que en el caso de Córdoba, esa información se encuentra contenida solamente en la ordenanza que regula el proceso participativo, escrita en lenguaje jurídico. En lo que respecta a los objetivos del PP, Morón y Rosario los explicitan de manera clara y ordenada, con enlaces propios los llamados "Objetivos", en el caso de Morón, y los “Fundamentos”, en el caso de Rosario. En la página de Córdoba no se encuentran consignados los objetivos.

En cuanto al lenguaje que se utiliza para producir la información, es recomendable que sea cercano y amigable para el usuario, redactado de forma clara y sencilla para agilizar la lectura. En el caso de Córdoba, el lenguaje es neutro y la redacción sencilla, pero la ordenanza donde el ciudadano debe remitirse para obtener detalles del proceso participativo, esto es, donde se encuentra la explicación de qué es y cómo funciona el PP está escrita en lenguaje jurídico (es una ordenanza), por lo que demanda contar con cierto vocabulario técnico para comprenderla en su totalidad. En los casos de Rosario y Morón, el lenguaje y la redacción son sencillos y claros, además Rosario posee toda la información traducida a la lengua Quom. 
Otro dato que es interesante de conocer es quiénes son los actores que participan, para el usuario web que busca información sobre quién puede participar y quienes participan o han participado en su región o barrio, ya que ese registro puede generar datos de contacto para promover otras instancias de participación y articulación. Además, esto daría cuenta también de la cantidad de asistentes y permitiría llevar un control sobre el proceso en general y su evaluación en términos de aumento -o no- de la participación. Las páginas de Rosario y Morón, publican la cantidad de asambleas realizadas y a la cantidad de participantes. En Rosario está disponible la cantidad de votos que recibió cada proyecto y un detalle de la cantidad de asistentes en versión .pdf para descargar desde la biblioteca. El municipio de Morón también lleva el registro de participantes por año, expresado en números enteros y expresados en términos porcentuales mostrando aumento o merma respecto a los años anteriores. En ningún caso se pone a disposición de los 'vecinos' el listado de los delegados resultantes en las diferentes instancias, mucho menos alguna forma de contacto posible con los mismos.

En lo que respecta a la forma de nombrar a los actores involucrados, en todas las publicaciones de las páginas se usa la palabra "vecino" como sinónimo de "ciudadano", lo cual demandaría avanzar, en futuros análisis, sobre los sentidos atribuidos a la noción de vecino en cada uno de los casos y sus implicancias para los procesos democráticos implementados.

Otro tipo de contenido que es importante que aparezca es la información sobre el estado de las obras votadas, lo que permite el monitoreo ciudadano no solo de los que continúan participando de manera directa a lo largo del proceso, sino también de los ciudadanos en general. En Rosario, en la sección "Biblioteca”, están todos los archivos que contienen las ejecuciones de obras (según criterios de la ejecución presupuestaria) y los proyectos votados disponibles para descargar en .pdf, además de informar sobre los proyectos votados y obras concretadas en la sección noticias. En la página moronense la información sobre las obras pautadas, ejecutadas y a ejecutar debe buscarse en la sección noticias. El avance y ejecución en la página de la municipalidad 
de Córdoba es confuso, debido a la coexistencia de dos diseños (el de la gestión actual y el de la anterior) y la falta de fechas en las publicaciones. También es posible conocer la concreción de algunas obras, por las publicaciones realizadas en la sección noticias del home, en las que generalmente se informa las actividades desarrolladas por el intendente.

En este sentido, es importante señalar que una de las características que define a internet como medio de comunicación es su capacidad de actualización. Bajo esta premisa e incorporando el concepto de inmediatez, han surgido herramientas como Twitter, aplicaciones de búsqueda como google instant search, ${ }^{13}$ software de transmisión o streaming, ${ }^{, 4} \mathrm{O}$ aplicaciones para teléfonos móviles como whatsapp, ${ }^{15}$ para mencionar algunas. La actualización y la inmediatez son -además de características propias de internet- las ventajas distintivas del medio. En los casos que estamos analizando, entonces, es esperable que la información esté actualizada para que cumpla con el requisito de oportunidad, de manera de extender el proceso participativo de la priorización de las obras al monitoreo continuo de su ejecución. En ese sentido, se observan distintos ritmos de actualización entre las páginas, tal vez asociados a los propios ritmos que asume la implementación del proceso participativo.

Más específicamente, relacionado con lo último que afirmamos, observamos la publicación de cronogramas de asambleas, dato que consideramos necesario para ampliar la convocatoria (más allá de las formas de comunicación directa, propia de estos espacios) y hacer efectiva la participación. Tanto las páginas de Morón como la de Rosario, anuncian la inminencia del comienzo del proceso, así como las fechas, horarios y direcciones de las distintas reuniones que tendrán lugar a lo

\footnotetext{
13 Consiste en la búsqueda sugerida que efectúa el buscador: al tipear las primeras letras de una palabra, se despliega un menú que contiene sugerencias de búsqueda que coinciden con esas letras. De esta manera la búsqueda se agiliza y se hace más fácil.

14 El streaming permite ver transmisiones radiales y televisivas en vivo y en directo por internet.

15 Es un sistema de mensajería gratuito que se utiliza con los teléfonos celulares. Actualmente pertenece a Facebook, que lo ha incorporado a su red.
} 
largo de la ciudad. En el caso de Córdoba, durante el período observado, fue publicado un cronograma que no contiene ninguna especificación sobre la naturaleza de la reunión a la que hace referencia.

En todos los casos, las oportunidades para el 'dialogo' se restringen a formas individuales definidas por las formas de ofrecidas (teléfono, correo electrónico). Ninguno de los casos avanzó, durante el período considerado, en la creación de foros o salas de chat que habiliten la interacción dialógica no solo ciudadano-funcionario, sino también ciudadano-ciudadano y/o ciudadano-funcionario-ciudadano. Lo que permitiría tanto el intercambio de información y saberes, como la integración y/u organización de aquellos ciudadanos que por primera vez se aproximan a la experiencia.

\section{Cuadro 6 - Contenidos}

\begin{tabular}{|c|c|c|c|}
\hline & CÓRDOBA & ROSARIO & MORÓN \\
\hline $\begin{array}{l}\text { Información básica sobre el } \\
\text { proceso }\end{array}$ & & $\mathrm{x}$ & $x$ \\
\hline El sitio está actualizado & & $x$ & $x$ \\
\hline Lenguaje adecuado & & $x$ & $x$ \\
\hline $\begin{array}{l}\text { Existencia de instancia de } \\
\text { diálogo }\end{array}$ & & & \\
\hline $\begin{array}{l}\text { Publicación de cronogramas } \\
\text { de asambleas }\end{array}$ & & $x$ & $x$ \\
\hline $\begin{array}{l}\text { Registro de la cantidad de } \\
\text { participantes }\end{array}$ & & $x$ & $x$ \\
\hline $\begin{array}{l}\text { Publicación de actas de } \\
\text { reunión }\end{array}$ & & & \\
\hline $\begin{array}{l}\text { Existe información sobre } \\
\text { proyectos }\end{array}$ & $x$ & $x$ & $x$ \\
\hline $\begin{array}{l}\text { Información sobre estado } \\
\text { de obras }\end{array}$ & $x$ & $x$ & $x$ \\
\hline $\begin{array}{l}\text { ¿De qué manera se refieren } \\
\text { a los ciudadanos? }\end{array}$ & $\begin{array}{l}\text { Usa "vecino" } \\
\text { como sinónimo } \\
\text { de "ciudadano". }\end{array}$ & $\begin{array}{l}\text { Usa "vecino" } \\
\text { como sinónimo } \\
\text { de "ciudadano". }\end{array}$ & $\begin{array}{l}\text { Usa "vecino" } \\
\text { como sinónimo } \\
\text { de "ciudadano". }\end{array}$ \\
\hline
\end{tabular}

Nota: Elaboración propia. 


\section{CONSIDERACIONES GENERALES}

La revolución tecnológica se expande aceleradamente y modifica la vida en la ciudad. Las TIC juegan un papel importante en esos cambios, ya que pasan a ser un factor esencial para que las personas se inserten plenamente en las sociedades. Por lo tanto, estas transformaciones trazan nuevas responsabilidades al poder público, que se ve obligado a concebir y realizar acciones que ayuden a los ciudadanos a acceder a la información, proveyendo de infraestructura y de servicios de información y comunicación de calidad. (RIBEIRO, et al, 2007)

En lo que respecta a los procesos de democratización de las decisiones colectivamente vinculantes, la incorporación de las TICs suma nuevas tensiones y complejidades que demandan ser tenidas en cuenta porque, como afirman Ribeiro e otros (2007, p. 52), "Esses recursos tecnológicos podem também provocar o aumento de desigualdades já existentes, sobretudo nos planos sócio econômico, educacional e cultural." En tal sentido sostienen: "O ideal é que seu uso se faça sob inflluência de conceitos que garantem os direitos humanos, como democracia, cidadania e identidade cultural, e que sejam usadas para promover a inclusao social, isto é, a plena participação dos indivíduos nas sociedades em que vivem".

En este trabajo exploramos las formas que asume la comunicación gubernamental en internet, particularmente, observando los sitios web de los municipios. Donde la proximidad física pareciera haber relevado, en la literatura y en la práctica, cualquier esfuerzo en las iniciativas gubernamentales por poner sobre relieve los elementos necesarios para consideración efectiva de todas las posiciones y la participación informada de todos los actores.

Es por eso que, apelando a la visibilidad, cognosibilidad y accesibilidad de las acciones gubernamentales y a la necesidad de su sometimiento al debate público, esto es, a la problematización ciudadana como ideal normativo, buscamos analizar las condiciones de factibilidad del acceso a la información pública, o más ampliamente, del derecho a la información en el ámbito público. Para lo cual pusimos énfasis en la identificación de indicadores vinculados a los atributos de 
los diseños y contenidos de las interfases generadas por los gobiernos locales.

Así, retomando discusiones anteriores, realizadas sobre acceso a la información y transparencia, resignificamos en este trabajo la noción de accesibilidad, de uso corriente en el campo de la discusión tecnológica. Para esto intentamos salir del análisis de las barreras derivadas centralmente de las condiciones físicas del sujeto usuario de la tecnología, para poner sobre relieve los limites contextuales que afectan la capacidad comunicativa de los sujetos en ese campo y, en tal sentido, demandar en la utilización del medio por parte de los gobiernos la generación de entornos amigables, comprensibles, eficaces y apropiados para los procesos participativos.

Con base en estas premisas observamos tres grandes dimensiones en las páginas web municipales: la identificación, la usabilidad y el contenido.

Así, de acuerdo a lo observado en cada caso, el trabajo comparativo sobre los tres sitios web de los municipios considerados -Córdoba, Rosario y Morón- evidencia diferentes niveles de desarrollo del medio, en relación al intercambio comunicativo iniciado por el gobierno para difundir y sostener los espacios participativos. En términos generales, podríamos establecer un arco entre las experiencias, que ofrece cierta complejidad en el caso de Rosario y grandes limitaciones en el caso de Córdoba. Aunque en todas puede afirmarse que el 'contexto' de implementación de las políticas tiñe la finalidad de la comunicación: la transparencia de resultados más que la información de procesos decisorios participativos. Privilegiando, entonces, el acceso a datos presupuestarios en el contenido, lo decidido, antes que a elementos que informen el proceso de toma de decisiones o que faciliten la integración/ articulación entre los ciudadanos en el propio proceso, para decidir lo que se va a hacer.

A partir de los atributos del diseño también creemos que es posible en este punto generar algunas hipótesis sobre el mensaje gubernamental que nos permitan continuar a futuro los análisis, considerando los 'vínculos' a los que se asocia el proceso participativo. Esto es, en 
principio, no se trataría de pensar solamente de los recorridos (cantidad de clicks) que demanda al ciudadano usuario de los sitios web llegar a la información sobre los espacios participativos y sus decisiones, sino también al 'posicionamiento' de la misma en relación a su propia relevancia, en cuanto generadora de voluntad colectiva directamente vinculante para la administración, o supeditada a las formas de la burocracia local. Todo lo cual nos permitiría hablar, en un segundo momento, de la pretensión democrática de la comunicación de los gobiernos que adoptaron iniciativas de apertura democrática de las decisiones, más allá de las características particulares que asumen la 'identificación', la 'navegabilidad' y el 'diseño' en cada uno de los casos. Y en tal sentido, todavía demandar, además de la publicidad de lo hecho, la divulgación de los datos relevantes (tales como vínculos a diagnósticos actualizados sobre las áreas de intervención estatal sometidas a debate) y el establecimiento de las condiciones necesarias, en el entorno de las TICs, para discutir sobre lo que se está haciendo y se va a hacer (información sobre participantes, habilitación de foros, divulgación de las actas de los espacios participativos, entre otros).

\section{REFERENCIA}

ANNUNZIATA, R. "Proximidad”, representación y participación:

El Presupuesto Participativo en Argentina Revista de Ciencias Sociales ICONOS, Quito/Ecuador, n. 40, Mayo, 2011.

ARANCIBIA, C. "Prefacio al concepto de comunicación política: una discusión bibliográfica”. Revista Investigación $\gamma$ Crítica, FLACSO, n. 4 , 2000 .

BUFFA, A.; ECHAVARRÍA, C. "La "transparencia" presupuestaria a partir de la experiencia de los municipios de la provincia de Córdoba”. Revista Studia Politicae, Córdoba, n. 22, dic./mar., 2010-2011.

BUFFA, A.; ECHAVARRÍA, C. Presupuesto Participativo, el debate en el marco institucional argentino. JORNADAS INTERNACIONALES DE FINANZAS PÚBLICAS. Córdoba, 2012. Actas... Universidad Nacional de Córdoba, Córdoba, 2012. 
CANEL, M. J.; SANDERS, K. Para estudiar la comunicación de los gobiernos: un análisis del estado de la cuestión. Rev Comunicación $Y$ Sociedad, v. 23, n. 1. p. 7-48, 2010.

CARVALHEIRO, J. R. "O triângulo bloqueado: media, política e cidadãos na democracia local”. En: CORREIA, J. C. (Org.). Comunicaçao e Política: estudos em comunicaçao. Covilhã: Ed. de la Universidade da Beira Interior, 2005.

DAGNINO, E. Concepciones de la ciudadanía en Brasil: proyectos políticos en disputa. En: CHERESKY, I. (Comp.). Ciudadanía, sociedad civil y participación política. Buenos Aires: Miño y Dávila, 2006. p. 387-410.

DAHLGREN, P. "Theory, Boundaries and Political Communication: The Uses of Disparity". European Journal of Communication, v. 19, n. 1, p. 7-18, 2004 .

DEMERS, F.; LAVIGNE, A. "La comunicación pública: una prioridad contemporánea de investigación”. Rev. Nueva Época, n. 7, ene./jun., p. $65-87,2007$.

ECHAVARRÍA, C. Presupuesto Participativo en Argentina: límites y potencialidades del relato cívico. In: CONGRESO ARGENTINO DE ADMINISTRACIÓN PÚBLICA, 6., Resistência/Argentina, 2011. Actas... Resistência, 2011a.

ECHAVARRÍA, C. De la eficiencia a la legitimidad: Contextos y actores de la participación en Argentina. Jalapa, México: Red de Análisis de Prácticas Participativas, 2011 b.

ECHAVARRÍA, C. ¿Aprendizajes democráticos y ciudadanos? Límites de las experiencias de implementación del Presupuesto Participativo en Argentina. In: ENCONTRO INTERNACIONAL PARTICIPAÇÃO, DEMOCRACIA E POLÍTICAS PÚBLICAS: APROXIMANDO AGENDAS E AGENTES. Araraquara, 2013. Actas... Araraquara, 2013.

ECHAVARRÍA, C.; MAURIZI, V. “La comunicación gubernamental: ¿herramienta para la legitimación de políticas o condición de posibilidad de la participación ciudadana?”. En: VALDÉS; MORALES (Comp.). Industrias culturales, medios y públicos: de la recepción a la apropiación. Córdoba: Universidad Nacional de Córdoba, 2013. COMPANAM. Escuela de Ciencias de la Información, UNC. Disponible en: <http://www.eci.unc.edu.ar/archivos/companam/ponencias/ 
Comunicaci\%C3\%B3n,\%2oPol\%C3\%ADtica\%2oy\%2oDerechos\%2o Humanos/ComunicacionyPolitica_echevarria.pdf>.

ECHAVARRÍA, C.; ROMANNUTTI, V. La factibilidad de la deliberación sobre los recursos públicos: diseños institucionales y prácticas de la ciudadanía en la ciudad de Córdoba. Revista Mas poder local, n. 20, jul. 2014 .

ELIZALDE, L.; FERNANDEZ PEDEMONTE, D.; RIORDA, M. La construcción del consenso. Buenos Aires: Ed. La Crujía, 2006.

FORD, A. Experimentos democráticos: asambleas barriales y presupusto participativo en Rosario, 2002/2005. Tesis doctoral. Programa de Doctorado en ciencias Sociales. FLACSO. Argentina, 2007.

FRANCÉS GARCÍA, F.; CARRILLO CANO, A. Guía metodológica propia de los Presupuestos Participativos. Alicante: Colectivo Preparacción, 2008.

GARNETT, J. “Comunicándose con la ciudadanía” En: IZURIETA, R. et al. Estrategias de comunicación para gobiernos. Buenos Aires: Crujia, 2003.

GASTIL, J. Political communication and deliberation. Estados Unidos: SAGE, 2008.

GERSTLÉ, J. La comunicación política. Santiago de Chile: Lom, 2005.

GRÖNLUND, A.; HORAN, T. A. "Introducing e-gov: History, definitions, and issues”, Communications of the Association for Information Systems,

v. 15, p. 713-729, 2004.

HABERMAS, J. Facticidad y Validez: una conversación sobre cuestiones de teoría política. En: HABERMAS, J. Más allá del Estado Nacional. Madrid: Trotta, 1997. p. 144-166.

INSTITUTO NACIONAL DE TECNOLOGÍAS DE LA COMUNICACIÓN. Guías prácticas de comprobación de accesibilidad: introducción a la accesibilidad web. España: INTECO, 2008. Disponible en: <https://www.incibe.es/file/bpoTrınHdohApbHgFsyFSw>. Acceso en: 25 marzo 2014 .

IZURIETA, R. "La comunicación política en la era del entretenimiento. Un estudio de la comunicación y las relaciones públicas para 
gobiernos". En: IZURIETA, R. et al. Estrategias de Comunicación para Gobiernos. Buenos Aires: Ed. La Crujía, 2002.

LAVIGNE, A. La politización de la información del sector público: propuesta de análisis. En: GAUTHIER, GROSSELIN Y MOUCHON (Comps.). Comunicación y política. Barcelona: Gedisa, 1998. P. 257-275.

SOBREIRA, R.; BORGES, J.; JAMBEIRO, O. "Políticas e gestão da informação pública: caso da Prefeitura de Salvador”. En: JAMBEIRO, O.; SILVA, H. P. da; BORGES, J. Cidades contemporâneas e políticas de informação e comunicações. Salvador: Edufba, 2007.

LANDER, E. Límites actuales del potencial democratizador de la esfera pública no-estatal. 2003. Disponible en: <http://unpanı.un.org/intradoc/ groups/public/documents/CLAD/UNPANooo177.pdf>. Acceso en: 17 marzo 2003 .

LATINOBARÓMETRO. Series de tiempo, ¿Cómo se informa de política? Disponible en: <http://www.latinobarometro.org/latOnline.jsp\#G2>. Acceso en: 17 marzo 2003.

LORANGER H. Infinite Scrolling is Not for Every Website. 2014. Disponible en: <http://www.nngroup.com/articles/infinite-scrolling/>. Acceso en: 17 jul. 2003.

NOBRE, G. Fráguas. "Capital social, comunicação pública e deliberação: a gestão do capital comunicacional público”. In: MAQUES, A.; MATOS, H. Comunicação e política. Capital social, reconhecimento e deliberação pública. Sao Paulo: Ed. Summus, 2011. p. 255-272.

PORTER, J. User Interface Engineering. 2013. Disponible en: <http:// www.uie.com/articles/three_click_rule/>. Acceso en: 17 jul. 2003.

RIBEIRO, A. P. et al. "Dilemas urbanos: municipalidades e políticas de informçao e comunicaçoes". In: JAMBEIRO, O.; SILVA, H. P. da; BORGES, J. Cidades contemporaneas e políticas de informação e comunicações. Salvador: Edufba, 2007.

RIORDA, M. Hacia un modelo de comunicación gubernamental para el consenso. En: ELIZALDE, L., FERNÁNDEZ PEDEMONTE, D.; RIORDA, M. (Ed.). La construcción del consenso. Gestión de la comunicación gubernamental. Buenos Aires: La Crujía, 2006. 
RIORDA, M. "Gobierno bien pero comunico mal: análisis de las Rutinas de la Comunicación Gubernamental”. Revista del CLAD Reforma Y Democracia, Caracas, v. 40, 2008.

USER INTERFACE ENGINEERING. 1997-2015. Disponible en: <http://www.uie.com>. Acceso en: 02 abr. 2014.

VEGA, H. La comunicación de gobierno e internet. En: IZURIETA, R; PERIA, R.; ARTERTON, C. (Comps). Estrategias de comunicación para gobiernos. Buenos Aires: Ediciones La Crujía, 2009.

WOLTON, D. La comunicación política: construcción de un modelo. En: FERRY, J.-M.; OLTON, D. et al. El nuevo espacio público. Barcelona: Gedisa, 1995 .

WORLD WIDE WEB CONSORTIUM. Disponible en: <http://www. w3.org/standards/webdesign/accessibility>. Acceso en: 02 abr. 2014. $\mathrm{W}_{3}$ C. Accessibility. 2015. Disponible en: <http://www.w3.org/standards/ webdesign/accessibility>. Acceso en: 02 abr. 2014. 